\title{
Matrix Metalloproteinases in Cytotoxic Lymphocytes Impact on Tumour Infiltration and Immunomodulation
}

\author{
Karin Edsparr • Per H. Basse • Ronald H. Goldfarb • \\ Per Albertsson
}

Received: 14 April 2010 / Accepted: 9 November 2010/Published online: 27 November 2010

(C) The Author(s) 2010. This article is published with open access at Springerlink.com

\begin{abstract}
To efficiently combat solid tumours, endogenously or adoptively transferred cytotoxic $\mathrm{T}$ cells and natural killer (NK) cells, need to leave the vasculature, traverse the interstitium and ultimately infiltrate the tumour mass. During this locomotion and migration in the three dimensional environment many obstacles need to be overcome, one of which is the possible impediment of the extracellular matrix. The first and obvious one is the subendothelial basement membrane but the infiltrating cells will also meet other, both loose and tight, matrix structures that need to be overridden. Matrix metalloproteinases (MMPs) are believed to be one of the most important endoprotease families, with more than 25 members, which together have function on all known matrix components. This review summarizes what is known on synthesis, expression patterns and regulation of MMPs in cytotoxic
\end{abstract}

K. Edsparr · P. Albertsson $(\bowtie)$

Department of Oncology, Sahlgrenska Academy,

University of Gothenburg, Göteborg,

SE-413 45, Göteborg, Sweden

e-mail: per.albertsson@oncology.gu.se

P. H. Basse

Hillman Cancer Center, University of Pittsburgh Cancer Institute, Pittsburgh, PA, USA

R. H. Goldfarb

Sopherion Therapeutics LLC,

Princeton, NJ, USA

P. Albertsson

Department of Radiation Oncology, Copenhagen University

Hospital, The Finsen Center, Rigshospitalet,

Copenhagen, Denmark lymphocytes and their possible role in the process of tumour infiltration. We also discuss different functions of MMPs as well as the possible use of other lymphocyte proteases for matrix degradation.

Keywords Cytotoxic lymphocyte - Natural killer cell . Matrix metalloproteinases · Proteases $\cdot \mathrm{T}$ lymphocyte . Tumour infiltration

\section{Matrix Metalloproteinases}

Matrix metalloproteinases (MMPs) are zinc-dependent enzymes of great importance for extracellular matrix (ECM) degradation and basal membrane (BM) penetration by lymphocytes $[1,2]$. This review summarizes the current data available regarding the reported repertoire of MMPs, their regulation in cytotoxic lymphocytes, $\mathrm{T}$ cells and natural killer (NK) cells as well as their impact on tumour infiltration and immunomodulation.

There are at least 25 described MMP members, all encoded by different genes. While there is substantial overlap in the MMP family with respect to specificity, they can be divided into four subgroups, i.e. interstitial collagenases (MMP-1, -8, -13 and MMP-18), gelatinases (MMP-2 and MMP-9), stromelysins (MMP-3, -10, -11, -7, -26 and MMP-27) and the membrane type MMPs (MT-MMPs) designated MT1-4 (MMP-14-17), MT5- (MMP-24) and MT6-MMP (MMP-25). The membrane bound MMPs are attached to the cell surface either through a single pass C-terminal transmembrane domain (as for MT1-, MT2-, MT3-, and MT5-MMP) or a glycosyl phosphatidylinositol (GPI) anchor (MT4- and MT6-MMP). 


\section{Matrix Metalloproteinases in Lymphocytes}

\section{Expression and Regulation of MMPs in NK Cells}

A variety of MMP members, namely MMP-1, $-2,-9,-13$, MT1-, MT2-, MT3- and MT6-MMP has been described to be expressed in freshly isolated human NK cells [3-6]. In addition, MMP-3, -7, -10 and -11 have been found to be expressed in rodent NK cells [7-10]. Detection of the various MMPs in NK cells has mainly been done by mRNA expression analysis, i.e. RT-PCR, while MMP-1, -2, -9, MT1- and MT2-MMP have been verified also on the protein level by gelatine zymography and Western blot $[3-5,7]$.

Even though many MMPs have been detected in NK cells, less is known about their regulation. NK cells has been shown to up-regulate their expression of MMP-2 upon cross-linking of the activating receptor $2 \mathrm{~B} 4$ [11] and the prostaglandin PGE2 enhances NK cell secretion of MMP-1 and MMP-3 and can thereby facilitates their migration through Matrigel filters [9]. The chemokine CXCL12 has further been found to enhance human NK cell invasion into type I collagen, as described to be in an MMP-1-dependent manner [4] and stimulation of human NK cells by the cytokine IL-18 increased their migration through Matrigel as well as their expression of MMP-2, -9 and MT1-MMP [5]. In human NK cells the effect of IL-2 is more difficult to study than in T cells, due to being ubiquous for NK cell culture. Using the IL-2-independent NK cell line YT to study the effects of IL2 on NK cells we found an early stimulatory effect on MMP9 secretion, and an enhanced migration through Matrigel. However, prolonged IL-2 stimulation resulted in reduced Matrigel invasion and a significant decrease in the expression of several MMPs. Thus, these in vitro data indicate a down-regulation of MMPs in response to continued cytokine stimulation. This may, in part, explain the reduced tumour infiltration by adoptively transferred NK and CD8+ T cells stimulated with IL-2 for 8-10 days compared to those stimulated with IL-2 for only 4-6 days [12]. Similarly, a prolonged culture of mouse T cells in IL-2 demonstrated a decreased anti-tumour activity in vivo [13].

\section{Expression and Regulation of MMPs in T Cells}

To date more is known about MMP regulation in T cells compared to NK cells. However, basically all publications in T cells concern MMP-2 and MMP-9 expression, where the latter is constitutively produced and MMP-2 is generated in response to antigen or cytokine stimulation [14-18]. Although, MMP-28, MT2-, MT3- and MT5-MMP have also been found to be expressed in $\mathrm{T}$ cell populations of $\geq 97 \%$ purity, by RT-PCR [19]. It could well be that the repertoire of MMPs in T cells is even larger, but has so far not been clearly reported on. For reference, in B cells, so far
MMP-3, MMP-9, MMP-26 and MMP-27 have been reported to be expressed [19-21], but also for this lineage of lymphocytes MMPs have not yet been thoroughly studied. To our knowledge expression of MMPs has not been verified in regulatory $\mathrm{T}$ cells (Tregs). However, a Treg-mediated inhibitory effect on MMP activity and adverse cardiac remodeling has been found using a murine model of myocardial infarction [22].

A vast variety of factors have been described to affect gelatinase production by $\mathrm{T}$ cells. MMP-2 is up-regulated through VCAM-1-dependent adhesion to endothelial cells [15] while MMP-9 is up-regulated by vasoactive intestinal peptide (VIP), the chemokines RANTES and MIP- $1 \alpha$, the prostaglandin PGE2, the leukotriene B4, TNF- $\alpha$, the phorbol ester 2-O-tetradecanoylphorbol-13-acetate (TPA), TGF- $\beta$ and the interleukin (IL)-2 [17, 18, 23-25]. On the other hand, IFN- $\beta$ as well as IFN- $\gamma$ have been found to repress the production of MMP-9 by T cells [17, 26, 27]. The NK and T cell activating cytokine IL-2 can in T cells increase MMP-9 production and MMP-dependent migration [14, 28]. Furthermore, increased collagenolysis was evident when IL-2 stimulated T cells were cultured with tumour cells but not in peripheral blood $\mathrm{T}$ cells [28]. Also, IL-8 increases the expression of MMP-2 and MMP-9 in human $T$ cells as well as their migratory ability [29]. Focal adhesion kinase (FAK) regulates integrindependent MMP-2 and -9 expression and release by T cells [30] and production of MMP-9 by $\mathrm{T}$ cells from tumour bearing mice increases in parallel to tumour burden, possibly via vascular endothelial growth factor (VEGF) [31].

Quantitative data on the secretion of MMPs are scarce but human $\mathrm{T}$ cells were found to produce higher amounts of MMP-2 and MMP-9 compared to NK cells [17]. However, this vast screening report using semi-quantitative gelatine zymography does not clearly adjust for difficulties ensuring cell viability in the necessary culture procedure. In fact, NK cells seem, from the current knowledge, to be better equipped to efficiently degrade a wide range of ECM structures due to the large variety of MMPs they express. We have found that while most MMPs detected in freshly isolated human NK cells are only moderately expressed, MT6-MMP is expressed at a much higher level than the other MMP members [6]. Most likely T- and NK cell migration has many common features and they probably use, at least partly, similar molecular machinery. Therefore, some of the findings for T cells might also apply for NK cells and vice versa. However, since no or only few direct comparing data are available such a statement has to await those studies.

\section{Localisation of MMPs}

It has been assumed that MMPs are released immediately following formation. However, pre-synthesized MT1-MMP 
has been proposed to be stored, transiently, in trans-Golgi network/endosomes of HT1080 fibrosarcoma cells awaiting trafficking to the cell membrane [32] and neutrophils have been shown to store MMP-8 and MMP-9 in granules that are rapidly released upon activation [33].

Cell surface containment of proteolytically active MMPs will optimize matrix degradation at the invasive front and, interestingly, also soluble MMPs may localize to the cell membrane. For instance, expression of membrane-bound MMP-8 was found to be up-regulated during neutrophil migration through Matrigel [34]. Furthermore, translocation of MMP-8 and MMP-9 to the cell surface of activated neutrophils was associated with an increased stability and a resistance to inhibition by tissue inhibitors of metalloproteinases (TIMPs) [34, 35]. Moreover, MMP-2, -7 and -9 have been shown to re-localize to the surface of malignant cells through association with proteoglycans, the proteoglycan-binding membrane receptor CD44 and integrin $\alpha v \beta 3$ [36-40]. Since activated cytotoxic lymphocytes also express CD44 and $\alpha v \beta 3$, it is fully possible that temporal cell surface retention of activated MMP members occurs in these cells via the same mechanism. Morphological evidence of MMPs in NK cells by antibody staining has proven very difficult, likely because of the low amounts of MMPs, and we have found no solid evidence for a granular storage of MMPs in NK cells despite extensive studies based on light and electron microscopy. However, by subcellular fractionation and subsequent gelatine zymography, evidence of a membrane localization of MMP-2 was obtained from the YT cell line [3].

\section{Utility of MMPs}

Matrix-degrading enzymes are known to be needed for the ability of malignant cells to invade dense matrices and the importance of MMPs in invasion has also been demonstrated in non-malignant cells e.g. vascular smooth muscle cells, keratinocytes, osteoclasts, macrophages and endothelial cells, reviewed in [2, 41-43].

In vitro studies of freshly isolated NK cells from human, mice and rats have shown that their migration through Matrigel depends in part on MMPs. Inhibition of freshly isolated human NK cell migration by the hydroxamate MMP-inhibitor GM6001 is in the 30\%-60\% range [4, 6]. Studies on rodent NK cells have shown that inhibition of MMPs using the MMP inhibitor batimastat (BB94) decreased rat A-NK cell migration by $50 \%$ while mouse A-NK cell migration was inhibited up to $70 \%-90 \%[7,8]$. The rat NK cell line RNK-16 has also been used to study the role of MMPs in NK cell migration and both GM6001 and BB94 inhibited their migration through Matrigel by approximately $50 \%[9,44]$. Likewise, invasion through Matrigel by $\mathrm{T}$ cells (both freshly isolated and cell lines) is facilitated by MMPs, since treatment with GM6001 or BB94 can reduce invasion by $30 \%-70 \%[14,23,24,45]$. Migration of T cells may also be reduced using selective gelatinase inhibitors in experimental models of inflammation [29].

The above mentioned studies all show an incomplete reduction of the migratory ability of both T- and NK cells using MMP inhibitors. Similarly, it has been demonstrated that cancer cells have an ability to traverse Matrigel despite presence of GM6001 [46], and that a capacity to invade Matrigel does not reflect invasive ability in vivo [47]. The here tested MMP inhibitors are not equally effective in inhibiting various MMPs and some might not be inhibited at all despite the high molar excess used in vitro. These findings could also be partly explained by the structural difference of Matrigel compared to authentic BMs, with a lower level of cross-linking, which consequently influences the relevance of Matrigel as a model of native BM. And, as later will be discussed, also other proteases and migration strategies do likely operate as well.

\section{Lymphocyte Locomotion in 3D Environment/Migratory Strategies}

Adhesion molecules have for long been considered a key component in facilitating and mediating lymphocyte homing and migration [48]. However, helped by the emergence of new and improved optical imaging technologies and the ease of gene knockout, new insights in cell locomotion in 3-dimensional matrices has been obtained. Much of the data has been obtained from dendritic cells acting as a model of leukocytes. Based on these studies, it has become clear that while attachment/adherence of lymphocytes to ECM for migration in 2-dimensional environments involves integrins, immune cells may well migrate in 3-dimensional matrices both in vitro and in vivo without the need for focal adhesion [49-52].

Lymphocyte migration in 3-dimensional matrices is now being described as amoeboid, i.e. a migration mode characterized by a rounded or ellipsoid cell shape with instable non-focalized adhesion sites and lack of stress fibres that allows the cells to migrate at high speed $(10 \mu \mathrm{m} /$ min) and squeeze through narrow matrix gaps [53-55]. If this is also the case in tumour tissue is yet to be shown, as here rapid tumour growth will lead to a disorganized morphology where possible normally present conductive traits or cellular pathways may become obstructed by either tightly packed tumour cells or an unstructured formation of matrix products from the malignant cells. In rodent experimental tumour models NK cells have been shown to deform into extremely thin formations during extravasation and intra-tumour migration, $\sim 3 \mu \mathrm{m}$, where the nucleus 
ultimately is size limiting [56, 57]. Very dense tumour tissue might not leave such gaps and could thereby physically resist lymphocyte invasion.

Less well documented, with only in vitro data using cultured mouse A-NK cells and human NK cell lines, is the possibility of a release of hydrophilic proteoglycancontaining material with matrix-dilating properties as a potential migratory strategy $[58,59]$. Such tissue-loosening effects have previously been demonstrated during mesenchymal cell migration and also to facilitate malignant cell invasion [60-62]. Clearly, there are many different components and several mechanisms involved in tissue migration, which could very well be operating in different situations or even simultaneously.

While the dependence of firm adhesion in 3-dimensional migration may be low, it is of high importance for the initial arrest in the microvessel and for extravasion across the endothelial lining [63, 64]. Although inhibition of proteases can cause a transition from protease-dependent migration to the amoeboid-like movement that allows cells to squeeze through narrow matrix gaps [65-67], the high density that characterizes basement membranes and some connective tissues makes it difficult to compensate matrix-degradation with shape change [68]. Therefore, lymphocytes migrating within tumour tissue, aiming at positioning themselves in direct contact with malignant cells, must likely depend on both matrix degradation and shape modulation.

Most lymphocyte-mediated killing mechanisms are dependent on a close contact between the immune cell and its target. It has however experimentally been shown that many extravasated lymphocytes remain localized in the stroma surrounding the tumour nests [57, 69-74]. This could be part of the explanation for the limited efficiency seen in adoptive immunotherapy [75]. Nevertheless, many of the lymphocytes do manage to migrate in between tumour cells and do establish close membrane contact with these. Whether the migrating lymphocyte needs cell-cell or cell-matrix interactions, or both, in order to receive the signals needed to continue its movement, is unclear. Thus, the extracellular matrix may thereby be seen as both a barrier and an important component to ensure forward propulsion. The arsenal of MMPs needed for an efficient migration of lymphocytes will likely vary with the ECM composition of the environment [76-78]. Thus, one could hypothesise that some lymphocytes are functionally deficient of the proteases needed to penetrate a specific tumour environment (an inverse of the "seed and soil" hypothesis proposed by Paget for the metastatic process [79]), which could contribute to a limited lymphocyte invasion. Since the exact preferred in vivo substrate for each MMP member is still mainly unknown, this issue is inherently difficult to study [80]. As to the question whether the presence of extracellular matrix is needed to ensure forward propulsion, we have observed significant migration of adoptively transferred IL-2-activated lymphocytes (LAK cells) of both T- and NK cell origin, into areas of tumours, which, appeared to be composed solely of tumour cells, i.e., with very little if any laminin, fibronectin and collagen [73] (Fig. 1). While the average density of LAK cells was found to be significantly higher in the ECM-rich tumours, ECMlow tumours also contained significantly more LAK cells than the surrounding normal lung tissue [73]. In the EMClow nodules, the density of LAK cells was higher in areas close to ECM elements (e.g., at the edge of the tumour or around blood vessels), but a substantial fraction of the LAK cells was found at distances greater than $100 \mu \mathrm{m}$ from the nearest, detectable matrix components. Thus, the presence of ECM may not be a prerequisite for the ability of activated lymphocytes to infiltrate and move around in solid tumours.

A number of studies have examined the ability of various lymphocytes to migrate into tumour-derived spheroids. For example IL-2 activated T- and NK cells have been investigated for their capacity to migrate into the intercellular space of a multicellular spheroid grown from a human glioblastoma [81]. In this system, migration was investigated via the use of different classes of inhibitors which had effect on various adhesion systems including cell-matrix or cell-cell interactions, e.g. $\alpha 3 \beta 1$ to fibronectin, laminin and collagen, but no such in vitro studies regarding proteases or protease inhibitors has been done.

\section{Microenvironmental Regulatory Factors}

Regulation of the MMPs occurs at several different levels, transcriptionally through induced or repressed expression, posttranscriptionally with proteolytic activation of the zymogen form and inhibition of the active enzyme by specific inhibitors. Also the extravasating lymphocyte may encounter several regulatory factors in the tumour microenvironment. Human NK cells infiltrating tumour nests have a relatively suppressed immunophenotype in contrast to the stromally located NK cells [82], which raises the question of the possibility of various subsets of effector cells. Further, there is an extensive cross-talk with other immune cells that will affect the lymphocytes activation status [83]. A number of reports have appeared that link the activation of MMPs to oxidative stress. For example, MMP inhibition has been suggested as a novel therapeutic strategy for the prevention of oxidative stress related damage to the heart [84]. In addition, high levels of oxygen radicals produced by tumour associated macrophages can suppress T- and NK cells cytotoxicity and viability [85]. A low $\mathrm{pH}$ level, which is often found within tumour tissue, has further been found to influence both lymphocytes 

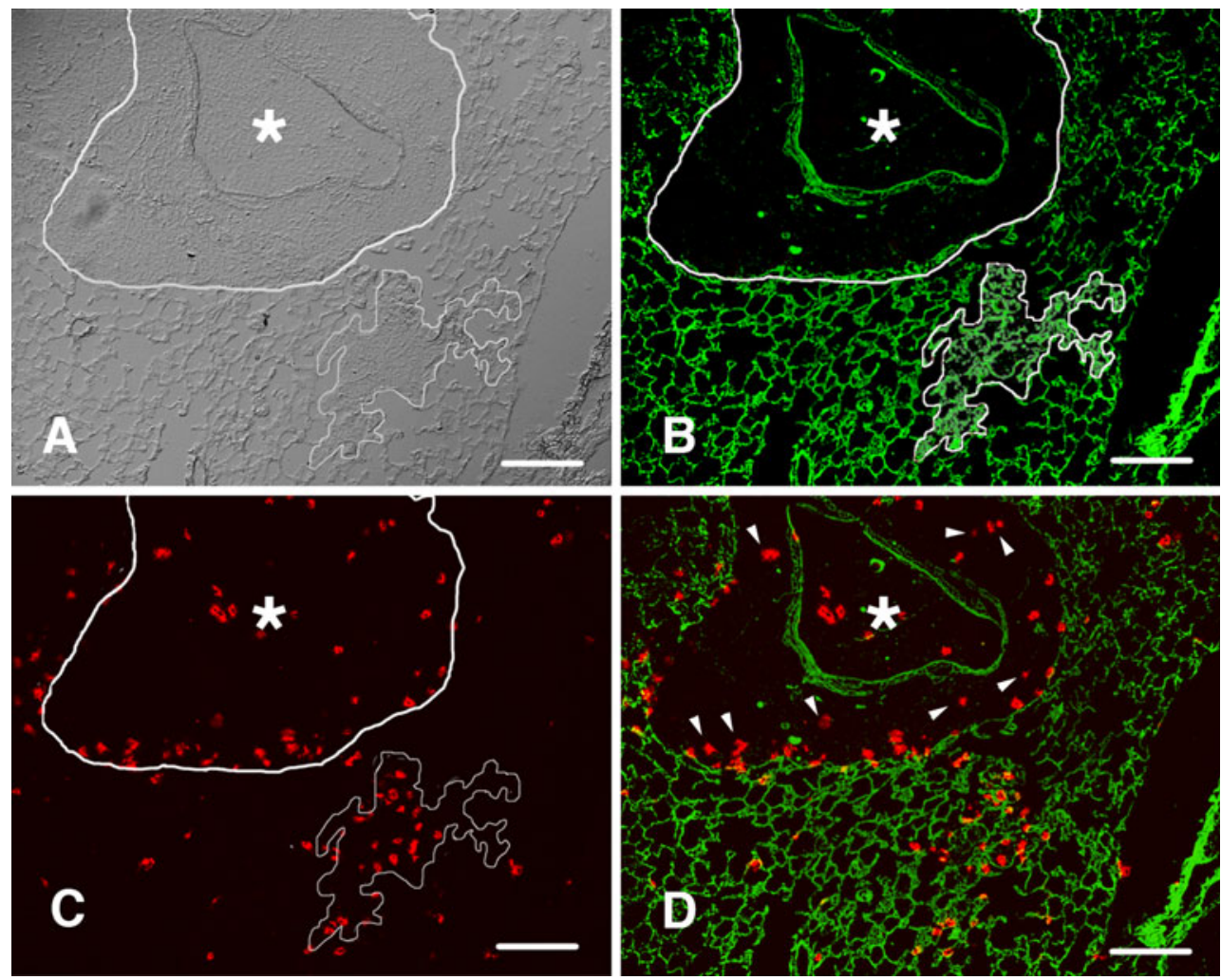

Fig. 1 LAK cell infiltration of lung metastases with high and low content of extracellular matrix components. Splenocytes from Thy $1.1+$ C57BL/6 congenic mice were incubated with IL-2. After 5 days of incubation, the cells, containing approximately equal amounts of NK cells, CD8+ T cells, and NKT cells, were harvested. $5 \times 10^{6}$ LAK cells were injected i.v. into Thy1.2+ C57BL/ 6 mice bearing 9 days old MCA-102 pulmonary metastases. 20,000 U Peg-IL-2 were given twice a day to support the injected cells. At $72 \mathrm{~h}$ after injection, lungs were removed, fresh frozen and cryosections were prepared. Sections were stained with PEconjugated anti-Thy1.1 antibody to reveal the LAK cells and with FITC-conjugated anti-Laminin antibody to reveal laminin. Tumours are outlined (white), a DIC (Differential interference contrast) photomicrograph of lung tissue showing a larger metastasis, growing around a vessel (asterisk), and a smaller, more pleomorphic

cytotoxic activity as well as their motility [86]. While a large decrease in $\mathrm{pH}$ has negative effects on lymphocyte activity, a slight decrease has been shown to increase IL-2activated $\mathrm{T}$ cells locomotion in in vitro ECM gels, indicating a finely tuned balance, the latter was suggested to be explained by an enhanced heparanase production [87].

Much has been written about the impact of a hypoxic environment on cellular chemotaxis and migration [88]. Hypoxia has been shown to suppress monocyte-derived dendritic cell MMP-9 [89]. In addition hypoxia has also been reported in multiple cellular systems to reduce MMP production. For instance, hypoxia has been found to reduce the output of TNF- $\alpha$-induced proMMP- 9 by three fold in a monocytic cell line and in primary human monocytes [90]. metastasis developing in the lung parenchyma with no relationship to larger vessels. b The same area as shown in A after staining with FITC-conjugated anti-laminin antibody. While the larger, perivascular metastasis contains very little laminin, the smaller, pleomorphic metastasis is rich in laminin. $\mathbf{c}$ The same area as shown in $\mathrm{A}+\mathrm{B}$ after staining with PE-conjugated anti-Thy 1.1 antibody. The density of LAK cells in the laminin-low, perivascular metastasis is substantially higher than in the surrounding normal lung tissue, but not as high as the density of LAK cells in the laminin-rich metastasis [73]. d Overlay of B and C: While the distribution of LAK cells in the laminin-rich nodule is relatively homogenous, the density of LAK cells is higher near laminin-dense areas of the laminin-low nodule. However, many LAK cells (arrow-heads) in the laminin-low nodule have migrated away from the laminin-rich edges and into what seems to be laminin-free areas. Bars $=200 \mu \mathrm{m}$

It has further been hypothesized that attachment of proMMP-9 to cell membranes is increased after hypoxia, consistent with its interactions with surface molecules such as CD44. Moreover, the reduced migration of monocytes in hypoxia was found to be mediated at least in part by secreted MMP-9 suggesting that hypoxia posttranslationally can reduce secreted amounts of proMMP-9 mostly by cellular trafficking but also by attachment to the membrane [90].

In vivo the extracellular source of active MMPs is intriguing. As known, tumour cells use MMPs and other matrix degrading proteases in their dissimination and in various steps of the metastatic process. And in malignant cell tissue invasion a substantial part of the matrix 
degrading proteases actually comes from surrounding stroma cells [91]. Similarly, T cell interaction with endothelial cells leads to MMP-2 activation, induced expression of MMP-9 and increased MMP-1 and MMP-3 expression in endothelial cells [92]. It has furthermore been shown that T cells induce MMP-1 [93] and MMP-9 [94] expression in monocytes and fibroblasts during co-culture. EMMPRIN/CD147 is a cell surface protein with extracellular metalloproteinase inducer activity. It is highly expressed in tumour cells and promotes MMP production by stromal cells. EMMPRIN/CD147 has been described to be expressed by human peripheral $\mathrm{T}$ cells $[95,96]$, however, the detailed function of EMMPRIN in invasion is still not well studied.

\section{Other Matrix-Degrading Enzymes}

Besides MMPs, the urokinase plasminogen activator (uPA) system is also implicated in ECM degradation and BM passage by lymphocytes $[1,2]$. The uPA system with uPA and its receptor uPAR contributes to ECM degradation by converting plasminogen into active plasmin, which degrades multiple matrix proteins and can also activate MMPs through proteolytic processing [97].

Extracellular and cell-associated plasminogen activators were first reported to be produced by highly purified NK cells with molecular characteristics including those of uPA suggesting a role for the uPA system in several aspects of NK cell function $[98,99]$. Through inhibition studies the uPA/uPAR system has been shown to be involved in rat NK cell migration, and there are evidence for a cooperation of the UPA system and MMPs in NK cell migration [44]. The uPA-uPAR system has further been showed to be involved in T cell invasion [100-102], indicating the importance of the uPA system in lymphocyte invasion. It has been suggested that UPAR is a signalling receptor and regulator of integrins in NK cells with impact on NK cell function [103]. Moreover, co-capping and fluorescence microscopy have shown that UPAR physically associates with the $\alpha v$ integrin on the surface of NK cells of the YT cell line [104]. This has suggested that signalling initiated by uPAR binding to UPA or by uPAR clustering may be dependent upon the physical association of UPAR with integrins.

Among other potential matrix degrading enzymes are the endoglycosidase heparanase. Heparanase is mostly produced by tumour cells, but also by lymphocytes [105] and a co-regulation between heparanase and MMP expression has been demonstrated [106, 107]. Of potential interest to study with references to the malignant cell invasion counterpart are seprase and elastase. While seprase is a membrane bound serine protease with gelatinase activity over expressed in malignant cells and found to associate with MMPs on the cell surface of tumour cells [108], elastase is a serine protease produced also by T cells [109].

The co-stimulatory antigen CD26, identical to the serine dipeptidylpeptidase IV, is induced on cytokine stimulated NK cells [110] and it has been proposed to participate in matrix degradation. Furthermore, the papain family of cystein peptidases cathepsin $\mathrm{B}, \mathrm{H}, \mathrm{L}, \mathrm{S}$ and the aspartic cathepsin $\mathrm{D}$, have been implicated in malignant behaviour contributing to matrix breakdown [111, 112] and the tetramer of related enzymatic subunits, dipeptidylpeptidase I (DPPI), is further found in the granules of cytotoxic lymphocytes [113], and has been implicated in degradation of matrix components [114].

Of particular interest, due to its relative abundance, is that the granular stored serine protease granzyme B, which is part of the extensive cytotoxic machinery in cytotoxic lymphocytes, has also been reported to degrade both noncollagenous and ECM-associated components including laminin, fibronectin, vitronectin and aggrecan proteoglycan $[115,116]$. While it is well recognized that the uPA system can degrade laminin and fibronectin as well as activate some latent pro-forms of MMPs, granzymes too might function in concert with lymphocyte MMPs to degrade the key ECM and BM components laminin and type IV collagen.

\section{Immunmodulating Effects of MMPs}

It has increasingly been recognized that the proteolytic action of MMPs is not restricted to only degradation of ECM components and that MMP therefore can be given an immunomodulating role. MMPs have been shown to selectively degrade non-matrix substrates including chemokines and cytokines and thereby contribute to cellular migration via multiple pathways [117]. Moreover, MMPs have now been found to be implicated in selective proteolysis of cell surface substrates, including integrins, growth factors and receptors [118]. Such selective proteolysis of non-matrix substrates, as well as ECM components, modulates many processes including tumour progression, cell survival and cell proliferation [1, 119, 120]. Importantly, the ECM may serve as a reservoir for growth factors and cytokines controlling their availability and activity. The highly important cytokine IL-2, has for example been shown to bind to collagen [121], and when released after collagenolytic activity it can provide a temporal important stimulation to the migrating T- or NK cells.

There are several mechanisms by which MMP-9 functions as a modulator to regulate the immune response. For example, MMP-9 can cleave and activate the cytokine IL-1, which induces the expression of MMP-9 in several cell types; it potentiates the effect of IL- 8 through truncation and can also 
cleave and inactivate the IL-2 receptor $\alpha$ chain [122]. Also, proteolytic processing of pro-TNF- $\alpha$ by MMP releases soluble TNF- $\alpha$ from the cell surface of peripheral blood mononuclear cells (PBMCs) [123].

\section{Future Perspectives}

This article reviews the pleiotropic functions of lymphocyte-derived MMPs in a number of killer cell functions. This includes but may not be limited to issues of cellular migration and localization of effector cells within the microenvironment of tumour metastases. In recent years quantitative peptidic-centric proteomic technologies, including those that recover N-terminal peptides have supplemented biochemical and genetic approaches for the identification of protease substrates; these have helped identify natural protease substrates while identifying their selective cleavage sites in complex backgrounds of thousands of distinct proteins [124]. As proteolytic processing receives increasing attention in the studies of signalling pathways as well as in cellular differentiation, protease substrates have also been sought via shotgun as well as mass spectrometry-driven substrate degradomics [125]. It has thus become increasingly clear that proteolysis mediated by MMPs and other lymphocytederived proteolytic enzymes are not limited to only the degradation of ECM substrates but can also be extended to a broader regulatory role via proteolysis of an array of additional physiological substrates. It is thus to be anticipated that future studies, for the identification of multiple substrates for proteolytic enzymes, will further illuminate the role for lymphocyte-derived proteases in numerous additional regulatory functions for these enzymes at both the cellular and molecular levels.

Open Access This article is distributed under the terms of the Creative Commons Attribution Noncommercial License which permits any noncommercial use, distribution, and reproduction in any medium, provided the original author(s) and source are credited.

\section{References}

1. Vaday GG, Lider O (2000) Extracellular matrix moieties, cytokines, and enzymes: dynamic effects on immune cell behavior and inflammation. J Leukoc Biol 67:149-59

2. Owen CA, Campbell EJ (1999) The cell biology of leukocytemediated proteolysis. J Leukoc Biol 65:137-50

3. Albertsson P, Kim MH, Jonges LE et al (2000) Matrix metalloproteinases of human NK cells. In Vivo 14:269-76

4. Goda S, Inoue H, Umehara $H$ et al (2006) Matrix metalloproteinase-1 produced by human CXCL12-stimulated natural killer cells. Am J Pathol 169:445-58
5. Ishida Y, Migita K, Izumi Y et al (2004) The role of IL-18 in the modulation of matrix metalloproteinases and migration of human natural killer (NK) cells. FEBS Lett 569:156-60

6. Edsparr K, Speetjens FM, Mulder-Stapel A et al (2010) Effects of IL-2 on MMP expression in freshly isolated human NK cells and the IL-2 independent NK cell line YT. J Immunother 33(5):475-81

7. Kim MH, Kitson RP, Albertsson P et al (2000) Secreted and membrane-associated matrix metalloproteinases of IL-2activated NK cells and their inhibitors. J Immunol 164:5883-9

8. Kitson RP, Appasamy PM, Nannmark U, Albertsson P, Gabauer MK, Goldfarb RH (1998) Matrix metalloproteinases produced by rat IL-2-activated NK cells. J Immunol 160:4248-53

9. Zeng L, An S, Goetzl EJ (1996) Selective regulation of RNK-16 cell matrix metalloproteinases by the EP4 subtype of prostaglandin E2 receptor. Biochemistry 35:7159-64

10. Kim MH, Albertsson P, Xue Y, Kitson RP, Nannmark U, Goldfarb RH (2000) Expression of matrix metalloproteinases and their inhibitors by rat NK cells: inhibition of their expression by genistein. In Vivo 14:557-64

11. Chuang SS, Kim MH, Johnson LA et al (2000) 2B4 stimulation of YT cells induces natural killer cell cytolytic function and invasiveness. Immunology 100:378-83

12. Kjaergaard J, Hokland M, Nannmark U, Hokland P, Basse P (1998) Infiltration patterns of short- and long-term cultured A-NK and T-LAK cells following adoptive immunotherapy. Scand J Immunol 47:532-40

13. Sussman JJ, Parihar R, Winstead K, Finkelman FD (2004) Prolonged culture of vaccine-primed lymphocytes results in decreased antitumor killing and change in cytokine secretion. Cancer Res 64:9124-30

14. Leppert D, Waubant E, Galardy R, Bunnett NW, Hauser SL (1995) $\mathrm{T}$ cell gelatinases mediate basement membrane transmigration in vitro. J Immunol 154:4379-89

15. Romanic AM, Madri JA (1994) The induction of $72-\mathrm{kD}$ gelatinase in $\mathrm{T}$ cells upon adhesion to endothelial cells is VCAM-1 dependent. J Cell Biol 125:1165-78

16. Goetzl EJ, Banda MJ, Leppert D (1996) Matrix metalloproteinases in immunity. J Immunol 156:1-4

17. Johnatty RN, Taub DD, Reeder SP et al (1997) Cytokine and chemokine regulation of proMMP-9 and TIMP-1 production by human peripheral blood lymphocytes. J Immunol 158:2327-33

18. Weeks BS, Schnaper HW, Handy M, Holloway E, Kleinman HK (1993) Human T lymphocytes synthesize the $92 \mathrm{kDa}$ type IV collagenase (gelatinase B). J Cell Physiol 157:644-9

19. Bar-Or A, Nuttall RK, Duddy M et al (2003) Analyses of all matrix metalloproteinase members in leukocytes emphasize monocytes as major inflammatory mediators in multiple sclerosis. Brain 126:2738-49

20. Di Girolamo N, Tedla N, Lloyd A, Wakefield D (1998) Expression of matrix metalloproteinases by human plasma cells and B lymphocytes. Eur J Immunol 28:1773-84

21. Trocme C, Gaudin P, Berthier S, Barro C, Zaoui P, Morel F (1998) Human B lymphocytes synthesize the 92-kDa gelatinase, matrix metalloproteinase-9. J Biol Chem 273:20677-84

22. Dobaczewski M, Xia Y, Bujak M, Gonzalez-Quesada C, Frangogiannis NG (2010) CCR5 signaling suppresses inflammation and reduces adverse remodeling of the infarcted heart, mediating recruitment of regulatory $\mathrm{T}$ cells. Am J Pathol 176:2177-87

23. Leppert D, Hauser SL, Kishiyama JL, An S, Zeng L, Goetzl EJ (1995) Stimulation of matrix metalloproteinase-dependent migration of T cells by eicosanoids. Faseb J 9:1473-81

24. Xia M, Leppert D, Hauser SL et al (1996) Stimulus specificity of matrix metalloproteinase dependence of human $\mathrm{T}$ cell migration through a model basement membrane. J Immunol 156:160-7 
25. Zhou H, Bernhard EJ, Fox FE, Billings PC (1993) Induction of metalloproteinase activity in human T-lymphocytes. Biochim Biophys Acta 1177:174-8

26. Leppert D, Waubant E, Burk MR, Oksenberg JR, Hauser SL (1996) Interferon beta-1b inhibits gelatinase secretion and in vitro migration of human $\mathrm{T}$ cells: a possible mechanism for treatment efficacy in multiple sclerosis. Ann Neurol 40:846-52

27. Stuve O, Dooley NP, Uhm JH et al (1996) Interferon beta-1b decreases the migration of $\mathrm{T}$ lymphocytes in vitro: effects on matrix metalloproteinase-9. Ann Neurol 40:853-63

28. Montgomery AM, Sabzevari H, Reisfeld RA (1993) Production and regulation of gelatinase B by human T-cells. Biochim Biophys Acta 1176:265-8

29. El-Shabrawi Y, Walch A, Hermann J, Egger G, Foster CS (2004) Inhibition of MMP-dependent chemotaxis and amelioration of experimental autoimmune uveitis with a selective metalloproteinase-2 and -9 inhibitor. J Neuroimmunol 155:13-20

30. Segarra M, Vilardell C, Matsumoto K et al (2005) Dual function of focal adhesion kinase in regulating integrin-induced MMP-2 and MMP-9 release by human $\mathrm{T}$ lymphoid cells. Faseb $\mathrm{J}$ 19:1875-7

31. Owen JL, Iragavarapu-Charyulu V, Gunja-Smith Z, Herbert LM, Grosso JF, Lopez DM (2003) Up-regulation of matrix metalloproteinase-9 in $\mathrm{T}$ lymphocytes of mammary tumor bearers: role of vascular endothelial growth factor. J Immunol 171:4340-51

32. Zucker S, Hymowitz M, Conner CE, DiYanni EA, Cao J (2002) Rapid trafficking of membrane type 1-matrix metalloproteinase to the cell surface regulates progelatinase a activation. Lab Invest $82: 1673-84$

33. Mollinedo F, Pulido R, Lacal PM, Sanchez-Madrid F (1991) Mobilization of gelatinase-rich granules as a regulatory mechanism of early functional responses in human neutrophils. Scand J Immunol 34:33-43

34. Owen CA, Hu Z, Lopez-Otin C, Shapiro SD (2004) Membranebound matrix metalloproteinase- 8 on activated polymorphonuclear cells is a potent, tissue inhibitor of metalloproteinaseresistant collagenase and serpinase. J Immunol 172:7791-803

35. Owen CA, Hu Z, Barrick B, Shapiro SD (2003) Inducible expression of tissue inhibitor of metalloproteinases-resistant matrix metalloproteinase-9 on the cell surface of neutrophils. Am J Respir Cell Mol Biol 29:283-94

36. Brooks PC, Stromblad S, Sanders LC et al (1996) Localization of matrix metalloproteinase MMP-2 to the surface of invasive cells by interaction with integrin alpha $\mathrm{v}$ beta 3 . Cell 85:683-93

37. Koyama Y, Naruo H, Yoshitomi Y et al (2008) Matrix metalloproteinase-9 associated with heparan sulphate chains of GPI-anchored cell surface proteoglycans mediates motility of murine colon adenocarcinoma cells. J Biochem 143:581-92

38. Rolli M, Fransvea E, Pilch J, Saven A, Felding-Habermann B (2003) Activated integrin alphavbeta3 cooperates with metalloproteinase MMP-9 in regulating migration of metastatic breast cancer cells. Proc Natl Acad Sci U S A 100:9482-7

39. Yu Q, Stamenkovic I (1999) Localization of matrix metalloproteinase 9 to the cell surface provides a mechanism for CD44-mediated tumor invasion. Genes Dev 13:35-48

40. Yu WH, Woessner JF Jr (2000) Heparan sulfate proteoglycans as extracellular docking molecules for matrilysin (matrix metalloproteinase 7). J Biol Chem 275:4183-91

41. Murphy G, Gavrilovic J (1999) Proteolysis and cell migration: creating a path? Curr Opin Cell Biol 11:614-21

42. Curran S, Murray GI (1999) Matrix metalloproteinases in tumour invasion and metastasis. J Pathol 189:300-8

43. Polette M, Nawrocki-Raby B, Gilles C, Clavel C, Birembaut P (2004) Tumour invasion and matrix metalloproteinases. Crit Rev Oncol Hematol 49:179-86
44. Al-Atrash G, Kitson RP, Xue Y, Goldfarb RH (2000) Cooperation of urokinase plasminogen activator and matrix metalloproteinases in NK cell invasion. In Vivo 14:565-70

45. Kim MH, Albertsson P, Xue Y, Nannmark U, Kitson RP, Goldfarb RH (2001) Expression of neutrophil collagenase (MMP-8) in Jurkat T leukemia cells and its role in invasion. Anticancer Res 21:45-50

46. Sodek KL, Brown TJ, Ringuette MJ (2008) Collagen I but not Matrigel matrices provide an MMP-dependent barrier to ovarian cancer cell penetration. BMC Cancer 8:223

47. Noel AC, Calle A, Emonard HP et al (1991) Invasion of reconstituted basement membrane matrix is not correlated to the malignant metastatic cell phenotype. Cancer Res 51:405-14

48. Butcher EC, Picker LJ (1996) Lymphocyte homing and homeostasis. Science 272:60-6

49. Lammermann T, Bader BL, Monkley SJ et al (2008) Rapid leukocyte migration by integrin-independent flowing and squeezing. Nature 453:51-5

50. Friedl P, Entschladen F, Conrad C, Niggemann B, Zanker KS (1998) CD4+ T lymphocytes migrating in three-dimensional collagen lattices lack focal adhesions and utilize betal integrinindependent strategies for polarization, interaction with collagen fibers and locomotion. Eur J Immunol 28:2331-43

51. Friedl P, Brocker EB (2000) T cell migration in threedimensional extracellular matrix: guidance by polarity and sensations. Dev Immunol 7:249-66

52. Hauzenberger D, Klominek J, Bergstrom SE, Sundqvist KG (1995) T lymphocyte migration: the influence of interactions via adhesion molecules, the T cell receptor, and cytokines. Crit Rev Immunol 15:285-316

53. Schmidt S, Friedl P (2009) Interstitial cell migration: integrindependent and alternative adhesion mechanisms. Cell Tissue Res 339(1):83-92

54. Friedl P, Wolf K (2010) Plasticity of cell migration: a multiscale tuning model. J Cell Biol 188:11-9

55. Lammermann T, Sixt M (2009) Mechanical modes of 'amoeboid' cell migration. Curr Opin Cell Biol 21:636-44

56. Basse PH, Nannmark U, Johansson BR, Herberman RB, Goldfarb RH (1991) Establishment of cell-to-cell contact by adoptively transferred adherent lymphokine-activated killer cells with metastatic murine melanoma cells. J Natl Cancer Inst 83:944-50

57. Nannmark U, Johansson BR, Bryant JL et al (1995) Microvessel origin and distribution in pulmonary metastases of B16 melanoma: implication for adoptive immunotherapy. Cancer Res 55:4627-32

58. Albertsson P, Basse PH, Edsparr K et al (2007) Differential locomotion of long- and short-term IL-2-activated murine natural killer cells in a model matrix environment. Scand J Immunol 66:402-9

59. Edsparr K, Johansson BR, Goldfarb RH et al (2009) Human NK cell lines migrate differentially in vitro related to matrix interaction and MMP expression. Immunol Cell Biol 87(6):489-95

60. Toole BP, Biswas C, Gross J (1979) Hyaluronate and invasiveness of the rabbit V2 carcinoma. Proc Natl Acad Sci U S A 76:6299-303

61. Pauli BU, Knudson W (1988) Tumor invasion: a consequence of destructive and compositional matrix alterations. Hum Pathol 19:628-39

62. Toole BP (1981) Glycosaminoglycans in morphogenesis. In: Hay ED (ed) Cell biology of the extracellular matrix. Plenum, New York, pp 259-94

63. Castermans K, Griffioen AW (2007) Tumor blood vessels, a difficult hurdle for infiltrating leukocytes. Biochim Biophys Acta 1776:160-74

64. Fisher DT, Chen Q, Appenheimer MM et al (2006) Hurdles to lymphocyte trafficking in the tumor microenvironment: implications for effective immunotherapy. Immunol Invest 35:251-77 
65. Wolf K, Muller R, Borgmann S, Brocker EB, Friedl P (2003) Amoeboid shape change and contact guidance: T-lymphocyte crawling through fibrillar collagen is independent of matrix remodeling by MMPs and other proteases. Blood 102:3262-9

66. Friedl P, Wolf K (2003) Proteolytic and non-proteolytic migration of tumour cells and leucocytes. Biochem Soc Symp 70:277-85

67. Wolf K, Mazo I, Leung H et al (2003) Compensation mechanism in tumor cell migration: mesenchymal-amoeboid transition after blocking of pericellular proteolysis. J Cell Biol 160:267-77

68. Sabeh F, Shimizu-Hirota R, Weiss SJ (2009) Protease-dependent versus -independent cancer cell invasion programs: threedimensional amoeboid movement revisited. J Cell Biol 185:11-9

69. Hagenaars M, Ensink NG, Basse PH et al (2000) The microscopic anatomy of experimental rat CC531 colon tumour metastases: consequences for immunotherapy? Clin Exp Metastasis 18:189-96

70. Kuppen PJ, Basse PH, Goldfarb RH, Van De Velde CJ, Fleuren GJ, Eggermont AM (1994) The infiltration of experimentally induced lung metastases of colon carcinoma CC531 by adoptively transferred interleukin-2-activated natural killer cells in Wag rats. Int J Cancer 56:574-9

71. Kuppen PJ, van der Eb MM, Jonges LE et al (2001) Tumor structure and extracellular matrix as a possible barrier for therapeutic approaches using immune cells or adenoviruses in colorectal cancer. Histochem Cell Biol 115:67-72

72. Okada K, Nannmark U, Vujanovic NL et al (1996) Elimination of established liver metastases by human interleukin 2-activated natural killer cells after locoregional or systemic adoptive transfer. Cancer Res 56:1599-608

73. Yang Q, Goding S, Hagenaars M et al (2006) Morphological appearance, content of extracellular matrix and vascular density of lung metastases predicts permissiveness to infiltration by adoptively transferred natural killer and T cells. Cancer Immunol Immunother 55:699-707

74. Yang Q, Hokland ME, Bryant JL et al (2003) Tumor-localization by adoptively transferred, interleukin-2-activated NK cells leads to destruction of well-established lung metastases. Int J Cancer 105:512-9

75. Albertsson PA, Basse PH, Hokland M et al (2003) NK cells and the tumour microenvironment: implications for NK-cell function and anti-tumour activity. Trends Immunol 24:603-9

76. David L, Nesland JM, Holm R, Sobrinho-Simoes M (1994) Expression of laminin, collagen IV, fibronectin, and type IV collagenase in gastric carcinoma. An immunohistochemical study of 87 patients. Cancer 73:518-27

77. Torimura T, Ueno T, Inuzuka S et al (1994) The extracellular matrix in hepatocellular carcinoma shows different localization patterns depending on the differentiation and the histological pattern of tumors: immunohistochemical analysis. J Hepatol 21:37-46

78. Wolf K, Alexander S, Schacht V et al (2009) Collagen-based cell migration models in vitro and in vivo. Semin Cell Dev Biol 20:931-41

79. Paget S (1989) The distribution of secondary growths in cancer of the breast. Cancer Metastasis Rev 8:98-101

80. Nagase H, Woessner JF Jr (1999) Matrix metalloproteinases. J Biol Chem 274:21491-4

81. Jaaskelainen J, Maenpaa A, Patarroyo M et al (1992) Migration of recombinant IL-2-activated $\mathrm{T}$ and natural killer cells in the intercellular space of human H-2 glioma spheroids in vitro. A study on adhesion molecules involved. J Immunol 149:260-8

82. Katou F, Ohtani H, Watanabe Y, Nakayama T, Yoshie O, Hashimoto K (2007) Differing phenotypes between intraepithelial and stromal lymphocytes in early-stage tongue cancer. Cancer Res 67:11195-201

83. Reschner A, Hubert P, Delvenne P, Boniver J, Jacobs N (2008) Innate lymphocyte and dendritic cell cross-talk: a key factor in the regulation of the immune response. Clin Exp Immunol $152: 219-26$

84. Schulz R (2007) Intracellular targets of matrix metalloproteinase2 in cardiac disease: rationale and therapeutic approaches. Annu Rev Pharmacol Toxicol 47:211-42

85. Hellstrand K (2003) Melanoma immunotherapy: a battle against radicals? Trends Immunol 24:232-3, author reply 4

86. Lardner A (2001) The effects of extracellular $\mathrm{pH}$ on immune function. J Leukoc Biol 69:522-30

87. Ratner S (1992) Motility of IL-2-stimulated lymphocytes in neutral and acidified extracellular matrix. Cell Immunol 139:399-410

88. Bosco MC, Puppo M, Blengio F et al (2008) Monocytes and dendritic cells in a hypoxic environment: spotlights on chemotaxis and migration. Immunobiology 213:733-49

89. Zhao P, Li XG, Yang M et al (2008) Hypoxia suppresses the production of MMP-9 by human monocyte-derived dendritic cells and requires activation of adenosine receptor $\mathrm{A} 2 \mathrm{~b}$ via cAMP/PKA signaling pathway. Mol Immunol 45:2187-95

90. Rahat MA, Marom B, Bitterman H, Weiss-Cerem L, Kinarty A, Lahat N (2006) Hypoxia reduces the output of matrix metalloproteinase-9 (MMP-9) in monocytes by inhibiting its secretion and elevating membranal association. J Leukoc Biol 79:706-18

91. Jodele S, Blavier L, Yoon JM, DeClerck YA (2006) Modifying the soil to affect the seed: role of stromal-derived matrix metalloproteinases in cancer progression. Cancer Metastasis Rev 25:35-43

92. Mach F, Schonbeck U, Fabunmi RP et al (1999) T lymphocytes induce endothelial cell matrix metalloproteinase expression by a CD40L-dependent mechanism: implications for tubule formation. Am J Pathol 154:229-38

93. Miltenburg AM, Lacraz S, Welgus HG, Dayer JM (1995) Immobilized anti-CD3 antibody activates $\mathrm{T}$ cell clones to induce the production of interstitial collagenase, but not tissue inhibitor of metalloproteinases, in monocytic THP-1 cells and dermal fibroblasts. J Immunol 154:2655-67

94. Aoudjit F, Esteve PO, Desrosiers M, Potworowski EF, St-Pierre Y (1997) Gelatinase B (MMP-9) production and expression by stromal cells in the normal and adult thymus and experimental thymic lymphoma. Int $\mathrm{J}$ Cancer 71:71-8

95. Ganor Y, Grinberg I, Reis A, Cooper I, Goldstein RS, Levite M (2009) Human T-leukemia and T-lymphoma express glutamate receptor AMPA GluR3, and the neurotransmitter glutamate elevates the cancer-related matrix-metalloproteinases inducer CD147/EMMPRIN, MMP-9 secretion and engraftment of Tleukemia in vivo. Leuk Lymphoma 50:985-97

96. Pistol G, Matache C, Calugaru A et al (2007) Roles of CD147 on $\mathrm{T}$ lymphocytes activation and MMP-9 secretion in systemic lupus erythematosus. J Cell Mol Med 11:339-48

97. Mazar AP, Henkin J, Goldfarb RH (1999) The urokinase plasminogen activator system in cancer: implications for tumor angiogenesis and metastasis. Angiogenesis 3:15-32

98. Carpen O, Saksela O, Saksela E (1986) Identification and localization of urokinase-type plasminogen activator in human NK-cells. Int J Cancer 38:355-60

99. Goldfarb RH, Timonen T, Herberman RB (1984) Production of plasminogen activator by human natural killer cells. Large granular lymphocytes. J Exp Med 159:935-51

100. Nykjaer A, Moller B, Todd RF 3rd et al (1994) Urokinase receptor. An activation antigen in human $\mathrm{T}$ lymphocytes. J Immunol 152:505-16

101. Kramer MD, Spring H, Todd RF, Vettel U (1994) Urokinase-type plasminogen activator enhances invasion of human $\mathrm{T}$ cells (Jurkat) into a fibrin matrix. J Leukoc Biol 56:110-6

102. Bianchi E, Ferrero E, Fazioli F et al (1996) Integrin-dependent induction of functional urokinase receptors in primary $\mathrm{T}$ lymphocytes. J Clin Invest 98:1133-41 
103. Gellert GC, Kitson RP, Goldfarb RH (2003) Urokinase-type plasminogen activator receptor crosslinking in an NK cell line increases integrin surface expression by the MAP kinase/ERK 1/2 signaling pathway. J Cell Biochem 89:279-88

104. Gellert GC, Goldfarb RH, Kitson RP (2004) Physical association of uPAR with the alphaV integrin on the surface of human NK cells. Biochem Biophys Res Commun 315:1025-32

105. Vlodavsky I, Eldor A, Haimovitz-Friedman A et al (1992) Expression of heparanase by platelets and circulating cells of the immune system: possible involvement in diapedesis and extravasation. Invasion Metastasis 12:112-27

106. Purushothaman A, Chen L, Yang Y, Sanderson RD (2008) Heparanase stimulation of protease expression implicates it as a master regulator of the aggressive tumor phenotype in myeloma. J Biol Chem 283:32628-36

107. Zcharia E, Jia J, Zhang X et al (2009) Newly generated heparanase knock-out mice unravel co-regulation of heparanase and matrix metalloproteinases. PLoS One 4:e5181

108. O'Brien P, O'Connor BF (2008) Seprase: an overview of an important matrix serine protease. Biochim Biophys Acta 1784:1130-45

109. Bristow CL, Lyford LK, Stevens DP, Flood PM (1991) Elastase is a constituent product of $\mathrm{T}$ cells. Biochem Biophys Res Commun 181:232-9

110. Yamabe T, Takakura K, Sugie K et al (1997) Induction of the 2B9 antigen/dipeptidyl peptidase IV/CD26 on human natural killer cells by IL-2, IL-12 or IL-15. Immunology 91:151-8

111. Sloane BF, Honn KV (1984) Cysteine proteinases and metastasis. Cancer Metastasis Rev 3:249-63

112. Gocheva V, Joyce JA (2007) Cysteine cathepsins and the cutting edge of cancer invasion. Cell Cycle 6:60-4

113. Thiele DL, Lipsky PE (1990) Mechanism of L-leucyl-L-leucine methyl ester-mediated killing of cytotoxic lymphocytes: dependence on a lysosomal thiol protease, dipeptidyl peptidase I, that is enriched in these cells. Proc Natl Acad Sci U S A 87:83-7
114. Wolters PJ, Laig-Webster M, Caughey GH (2000) Dipeptidyl peptidase I cleaves matrix-associated proteins and is expressed mainly by mast cells in normal dog airways. Am J Respir Cell Mol Biol 22:183-90

115. Buzza MS, Zamurs L, Sun J et al (2005) Extracellular matrix remodeling by human granzyme B via cleavage of vitronectin, fibronectin, and laminin. J Biol Chem 280:23549-58

116. Froelich CJ, Zhang X, Turbov J, Hudig D, Winkler U, Hanna WL (1993) Human granzyme B degrades aggrecan proteoglycan in matrix synthesized by chondrocytes. J Immunol 151:7161-71

117. Van Lint P, Libert C (2007) Chemokine and cytokine processing by matrix metalloproteinases and its effect on leukocyte migration and inflammation. J Leukoc Biol 82:1375-81

118. Cauwe B, Van den Steen PE, Opdenakker G (2007) The biochemical, biological, and pathological kaleidoscope of cell surface substrates processed by matrix metalloproteinases. Crit Rev Biochem Mol Biol 42:113-85

119. McCawley LJ, Matrisian LM (2001) Matrix metalloproteinases: they're not just for matrix anymore! Curr Opin Cell Biol 13:534 40

120. Mott JD, Werb Z (2004) Regulation of matrix biology by matrix metalloproteinases. Curr Opin Cell Biol 16:558-64

121. Somasundaram R, Ruehl M, Tiling N et al (2000) Collagens serve as an extracellular store of bioactive interleukin 2. J Biol Chem 275:38170-5

122. Opdenakker G, Van den Steen PE, Van Damme J, Gelatinase B (2001) a tuner and amplifier of immune functions. Trends Immunol 22:571-9

123. Gearing AJ, Beckett P, Christodoulou M et al (1995) Matrix metalloproteinases and processing of pro-TNF-alpha. J Leukoc Biol 57:774-7

124. Van Damme P, Vandekerckhove J, Gevaert K (2008) Disentanglement of protease substrate repertoires. Biol Chem 389:371-81

125. Impens F, Colaert N, Helsens K et al (2010) MS-driven protease substrate degradomics. Proteomics 10:1284-96 